\title{
A Theoretical Appraisal of Political Behavior: Actors, Processes and Consequences
}

\author{
Hamd Ejaz \\ Bloomfield Hall \\ Email: Hamdejaz88@gmail.com
}

\begin{abstract}
The study of political behavior constitutes a vast subject. Political behavior has many subjected to multiple paradigm shifts of research and the outcome has always been a formation of new theories which explain how the political behavior taking place at all levels of analysis- global, regional, and national and individual levels, has evolved. Political behavior has been sometimes oversimplified to include behavior which is related to legislation in one way or another. It is for this purpose, that this paper differentiates between 'social', 'economic' and 'political' behavior and points out how there can be multiple areas of convergences between all of them. Mostly, this paper presents the various modern theoretical precepts related to political behavior in a holistic manner so as to cover the topic by adopting a multi-disciplinary approach. Therefore, the subject in question, borrows concepts from a range of disciplines including political sociology and political psychology to explain how socialization is rooted in political culture and how it is transformed into 'public will'- as quoted by Rousseau through the processes of voting. The paper will also seek to explain the possible degenerate forms of political behavior including political violence, genocide and political alienation.
\end{abstract}

Keywords: Political Behavior, Political Culture, Political Socialization, Political Participation, Political Parties.

\section{Introduction}

Political behavior has been defined by the Oxford Handbook of Political Psychology as:

"Political behavior, is largely a part of political science which seeks to explain and generalize the numerous influences on an individual's political viewpoints: such as norms and values, ideology and political participation. Behavior is political mostly when individuals or groups interact in order to dominate or evade influence. In that sense, human behavior when considered under the pretext of authority is political." (O'Sears, 2003)

The above mentioned definition provides a working valuation of the various markers and processes which identify collectively the process of political participation. On the basis of this definition, then, it is important that a discussion be included of the various components of political behavior.

Before we embark on the journey of discussing the concept of political behavior fully, it is necessary to differentiate between 'Social Behavior', 'Economic Behavior' and 'Political Behavior'.

Social behavior is more general than economic behavior and political behavior. Social behavior is concerned with interaction, interrelationships with the society in general, with no particular emphasis on economic transactions or governmental authority. Social behavior is very important since it is how individuals deal with one or another.

Economic behavior can be defined as any action regarding the marketplace i.e. any act of production, consumption or distribution. For example, the act of purchasing a textbook can be called as economic behavior.

Political behavior can be defined as any action regarding authority in general and government in particular. The authority may include church, school but specifically it includes governmental authority. For example, the act of voting is a political behavior and so are protests, demonstrations and roadblocks. 
Now that these behaviors have been separated, it is necessary to understand that while these behaviors are separate these may be connected. Political behavior is almost always directly related to economic behavior. For example, many people choose not to vote because the act of voting did not bring any change in their economic condition. Social behavior is closely related with economic conditions. For example, an unemployed individual may not have smooth relationship with other members of the society because of economic frustration.

\section{Historical Overview of the Study of Political Behavior}

Over the period of decades, there has been a shift in focus on studying different aspects of political behavior. Political behavior in its most rudimentary form was studied as the histories of political elites in the form of psychobiography and psychohistory. This was the trend in political science in 1940s and 1950s as the political scientists and political psychologists attributed the horrors of World War Two to authoritarian personalities. It was believed then, under the perverse influence of Freud's Psychodynamic perspective that childhood trauma is responsible for engendering the markers of political violence. The trend shifted towards studying political attitudes and voting behavior in 1960s and 1970s. In the 1980s and 1990s the focus of studying political behavior was to understand the content and processes of various belief systems or political ideologies. (Cottam, 2007)

A table has been given below to better understand the varying trends of studying political behavior in different perspectives:

\begin{tabular}{|l|l|l|l|}
\hline ERAS & $\begin{array}{l}\text { FEATURES OF POLITICAL } \\
\text { BEHAVIOR }\end{array}$ & THEORIES MOSTLY USED & METHODS PREFERRED \\
\hline $\begin{array}{l}1940 \mathrm{~s} \\
\text { and } \\
1950 \mathrm{~s}\end{array}$ & $\begin{array}{l}\text { Political Personality of Leaders } \\
\text { and Masses }\end{array}$ & $\begin{array}{l}\text { Stimulus-Response theories, } \\
\text { Psychoanalysis, Marxism and } \\
\text { Behaviorism }\end{array}$ & $\begin{array}{l}\text { Content Analysis based on } \\
\text { Interviews and } \\
\text { biographies. }\end{array}$ \\
\hline $\begin{array}{l}1960 \mathrm{~s} \\
\text { and } \\
1970 \mathrm{~s}\end{array}$ & $\begin{array}{l}\text { Voting Behavior and } \\
\text { Underpinning Political Attitudes } \\
\text { ational Actor Model, } \\
\text { Cognitive Affect. }\end{array}$ & $\begin{array}{l}\text { Questionnaires i.e Feeling } \\
\text { thermometers, Observational } \\
\text { techniques including participant } \\
\text { observation. }\end{array}$ \\
\hline $\begin{array}{l}\text { 1980s } \\
\text { and }\end{array}$ & $\begin{array}{l}\text { The Content and Processes } \\
\text { underlying Political Behavior i.e. } \\
\text { belief systems residing within } \\
\text { Political Ideology }\end{array}$ & $\begin{array}{l}\text { Information Pecision Making Theories } \\
\text { Risk Indulgent and Risk } \\
\text { Aversive Behavior) }\end{array}$ & $\begin{array}{l}\text { Experimental variations in } \\
\text { Controlled and Field Settings. }\end{array}$ \\
\hline
\end{tabular}

Source: (Cottam, 2007)

\section{Actors}

\section{A. Political Parties}

There is a plethora of different opinions regarding religion, government, speculation as well as practice, individuals who compete for eminence and power. These opinions which have an incredible variety and appeal to a host of different human passions have divided mankind into parties, in which humans have oppressed and cooperated with each other.

James Madison noted in The Federalist Papers that there are many and various causes due to which people form parties, through which they achieve objectives which are impossible to achieve on their own. James Madison argues that 'The latent causes of faction are sown in the nature of man.' Therefore, to James Madison the principal task of government becomes to regulate and reconcile the various and interfering interests that encourage groups to form and to seek their own advantage at the expense of others. George Washington argued in 1796 that:

"Let me...warn you in the most solemn manner against the baneful effects of the spirit of party." ( DeZavala, 2010)

Today, it is impossible to imagine democracies without the mediums of parties. The party which represents the norms which are closest to the public gets the highest number of votes. The politicians who then get elected promote the interests of the public.

The dynamics of parties are influenced by the social and political context in which they operate. At the most basic level, a party which faces no competition is markedly different than a party system rooted in pluralism. One-party 
systems included the communist parties operating in the Communist China and USSR. These parties exercised a monopoly over power which is used to guide the working class to a state of communism, in which there is no point for coercion. Such a party must be extremely centralized and pervasive so as to infiltrate every layer of society in order to supervise the citizens. The party uses indoctrination and censorship to maintain its dominance and crush dissent.

In a one party system, there is no need to compete for control of the apparatus of government since it is an apparatus of the government in a way. In multi-party systems, the basic purpose of the party is to win the elections by getting the most number of votes and then govern the people. In democracy, since the will of the government should be the same as that of the people, therefore representation becomes an issue in large countries like USA. Therefore, elections are fought out after periodic intervals. Belonging to a party is a description of values that are expected of the candidate (O'Sears, 2003). It may be an indication of how a candidate will act during political activities. Party discipline is a very prominent feature of multi-party systems.

USA and UK have two-party systems but the term 'two-party systems' can be misleading since there is a third party 'Liberal Democrats' in UK. However, the dominant political competition has been between the Labor and Conservative party. The winning party is not required to achieve an absolute majority therefore; it results into a strong party which can enforce its political agenda. H.L. Mencken said in 1956:

"Under democracy one party always devotes its chief energies to trying to prove that the other party is unfit to rule-and both commonly succeed, and are right." (Boix Charles M., 2007)

Other democracies often use proportional representation instead of pluralist majority, which gives a fighting chance to the smaller parties. The resulting government is usually a coalition of different political parties and they must work together to command a governing majority. These coalitions are more volatile and less stable than single party governments usually seen in pluralist majority voting systems. While coalitions of this kind may be short lived and fragile, they may also be dynamic and innovative.

Today the major parties of the United States and Europe appear dull and out of touch to the young. The motives of the politicians are often cast into doubt courtesy of the regular charges of corruption and hypocrisy. Due to all of this, popular support seems diminished and parties now resort to seek middle ground and please everyone. Equally important are the new platforms of communication which give way to political expression undermining the traditional monopoly enjoyed by the political parties. Modern democracies may be hard to imagine without political parties but these parties have to reconnect with new generation of voters (Woshinsky, 2008).

\section{B. Lobbyists and Pressure Groups}

Individual on their own have little influence in politics. When individuals combine together, only then can they have an impact on politics. This is the behavior adopted by individuals in democracies. Individuals organize themselves into huge numbers using their rights of assembly and a variety of voluntary organizations such as professional and business organizations, trade unions, churches, environmental groups, youth clubs and community associations. These voluntary organizations are said to be the main foundations of a modern democracy. These groups voice the demands of the groups they represent in the political arena and are themselves organized around the interests of social groups and strata.

So, pressure groups can be defined as private and voluntary organizations that try to influence or control government policies but do not want to become the government themselves. Pressure group is a very general term. 'Lobby' is also another popular term for a pressure group which is based on the mistaken belief that pressure group representatives spend a lot of time in the 'lobbies' or ante-rooms of legislative chambers.

Pressure groups perform two main functions: Interest aggregation and Interest articulation (Almond, 1965). Interest aggregation is the formation of a single policy program from a set of rather different interests and perspectives. For example, student organizations have to reconcile the interests of science and humanities students, first and higher degree students and home and overseas students. The role of sifting through opinions and presenting it as a single package is performed by pressure groups. Interest articulation is expression and publication of policies so as to influence the governmental policies. This is the function of giving 'voice to the masses' performed by the pressure groups (Woshinsky, 2008).The criteria through which some pressure groups become more influential than others can be divided into two categories: Group and Political structures.

Group structures can be different in the following ways: 
- Based on income: Some groups are wealthier than others and therefore can support a large staff. In most cases, interest groups are wealthier than cause groups since interest groups represent economic interests of the individuals and members are required to pay a subscription fee.

- $\quad$ Based on membership size: Large groups can collect membership subscriptions from many members but size alone cannot be the sole criterion for being more influential as some smaller groups are more cohesive than large fragmented groups.

- Based on organizational advantages: Some groups are easier to organize than others. A comparison of wealthy and the poor, doctors and the terminally ill, the young and the old elucidate the differences in organizing these diverse social groups.

- Based on membership density: A pressure group which represents all of its potential members is bound to have more influence than a group which does not represent all of its members. Many interest groups require $100 \%$ membership therefore lawyers and doctors associations have $100 \%$ membership density. A pressure group for the homeless does not have a $100 \%$ membership since it relies on a few dedicated activists, many of whom are not homeless themselves.

- Based on unity: A pressure group which is united and cohesive will have more influence than a fragmented group. Groups which are united by a single purpose by form an 'Umbrella group' which in turn coordinates the activity of their member organizations.

- Based on sanctions: Some pressure groups have powerful sanctions such as a business group which can move its entire capital to another country, professional associations which may withdraw cooperation with the government. Other groups may not have powerful sanctions such as patients cannot refuse medical treatment and homeless cannot refuse to pay the rent.

- Based on leadership: Some pressure groups are simply more powerful because they have charismatic leadership. Charismatic leaders who have led pressure groups include Martin Luther King and Nelson Mandela.

- Based on issue: Big controversial issues attract powerful pressure groups.

Political structures can have the following features:

- Based on 'Insider/Outsider' status: Insider groups are closer to top decision makers and therefore they are stronger than outsider groups.

- Based on public opinion: Pressure groups which have strong support in terms of public opinion are more likely to be powerful than those which do not have the support of public opinion.

- Based on legitimacy: Pressure groups which represent legitimate interests are more likely to have influence. Examples include doctors association and lawyers bar association. Marginal pressure groups such as those representing the interests of drug addicts and prostitutes are not likely to have same legitimacy.

- Based on political parties: Pressure groups which are aligned with the party which is in government are likely to have an 'insider' status and therefore wield greater power than those groups which are not based on political parties.

- Based on countervailing powers: Pressure groups which have other pressure groups in opposition with counter ideas and perspectives are less likely to succeed. Those pressure groups are more powerful which do not face any competition at all.

\section{Processes}

\section{A. Transference of Political Values from Political Culture}

Political culture can be defined as the attitudes, feelings, ideas, and values that people have about politics, government and authority in its various forms. Having that said, it is easy to understand that every country must have its own political culture, which varies from one country to another. For example, the attitude of a Pakistani citizen towards politics is different from the attitude of a French citizen towards politics (Ahmed Akbar S, 2010). 
Forms of government and political structures may be same between two countries but the political culture is always different since between politics and structures lies culture. Just as political culture cannot be the same between two countries; it cannot remain the same in a country. Political culture changes and evolves in response to domestic changes and international challenges.

Political culture and political behavior are closely related. Political behavior refers to actions in relation to authority; what an individual does or does not do. Therefore, it is easy to observe and note. Political culture refers to a belief system- attitudes and beliefs of a country. It is abstract.

It can be said that political culture can be deciphered from political behavior. But this is a simplistic assertion since most of the times our behavior is inconsistent with our beliefs. Nonetheless, the integral link between political culture and political behavior cannot be denied.

In general, political culture can be said to impact general attitudes and values, specific attitudes towards national institutions, attitudes towards political identity and attitudes towards political leadership.

\section{B. Political Socialization}

Political socialization can be defined as the process in which society develops attitudes and feelings towards politics in each of its members. Political socialization can be said to be equivalent to political upbringing. Political socialization takes place at two important levels: primary and secondary.

Primary political socialization can be said to be a resultant of relationships or processes that are informal, unstructured and unorganized. The first primary agent of socialization is the family or the household unit. The household unit exposes the individuals for the first time to political loyalties and political hostilities. The household unit also passes the attitude towards the country. At another level, the child is exposed to authority and power in the household. This exposure crystallizes the responses to authority. Therefore, the institution of family helps form attitudes towards authority.

Therefore, the more families break down, the more authority in the home disappears. Breakdown leads to erosion and decay. Erosion will lead to children having children. Parental authority is also absent because the parent is compelled to work around the clock. Family structures around the globe are being eroded so that political socialization is being negatively affected.

Second, most important agent of socialization is the 'peer group'. Members of peer group share relatively equal status and are clustered around a particular location. Peer groups influence mutual reinforcement of ideas in either negative or positive ways. Peer groups have a powerful way of political upbringing (Roy, 2014).

Secondary political socialization takes place through more formal institutions. The first agency is the school which effects politically in two ways:

a. It is the first organized effort to transmit politically relevant consciousness. Examples include teaching the national anthem, symbolism of the national flag and detailed parables of national heroes. Therefore, it is in the schools that symbols of nationhood and national authority is learned.

b. Schools form the first formal response to authority which exists in the form of teacher, principal and administrator.

The second important agency for socialization is the religious institution. Religion is more often than not the main source of our knowledge of which ideas are right and which ones are wrong. Religion also has a profound impact on how people view politics. Greater religiosity implies less degree of dishonesty and corruption in public behavior.

The third important agency for socialization is the mass media. Mass media includes radio, television, newspapers and internet. Talk shows are especially very important for forming people's attitudes and influencing their values (Hull, 2012).

The fourth important agency for socialization is the political party which the political leadership tries to develop certain attitudes and reinforce certain hostilities. The political party most often tries to socialize members to uphold and to support the party. 
It is important to note that not all socializing agencies have the same effect. The extent of importance they have is then again related to the cultural constraints in which it is being observed.

\section{Political Participation}

Political behavior is manifest in the form of political participation. Political participation can be defined as the extent to which the citizens use their rights i.e. right to vote, right to protest, right of free speech and right of political association. Political participation can be categorized into two types:

a) Conventional Political Participation: Conventional political participation is that form of political participation which takes place between the norms and traditions of a particular country. In principle, conventional political participation is normal, conventional and customary. Examples include casting vote and attending a political meeting.

b) Unconventional Political Participation: Unconventional political participation is that form of political participation which takes place outside the norm and tradition. This form of political participation is assertive, aggressive and at times outside the law. The best examples of this form of political participation are protests and demonstrations that are confrontational in nature (Huemer, 2013).

\section{Elections}

Elections normally determine who is going to take charge of the government. Elections are very important for research since they produce a large volume of reasonably reliable statistics and include a very large number of citizens. Elections show how ordinary citizens relate to politics, what they think is important and which important issues they think need to be resolved first.

However, elections require certain conditions which are very demanding. Only after fulfilling these conditions, can the elections be called 'Democratic Elections.' Voting normally takes place in two main forms; general elections for varying levels of political systems and referendum. Referendum can be defined as the submission of a public matter to direct popular vote. Referendums are used to express public opinion on certain important matters such as a constitutional change or a major policy change (Taylor G, 2004).

\section{Consequences}

A. Formation of Political IdeologyPolitical ideology is a closely linked component of political behavior. Political ideology is a belief system which in turn can be defined as cognitive components that constitute and shape our understanding of the way our social environment is shaped in (De Zavala, 2010). One example of a belief system is 'Free speech is a necessity'. It is important to distinguish between beliefs and values. Values are almost the same as beliefs with the distinctive quality of being idealistic. Beliefs refer to what individuals deem as true whereas values refer to what should be true or what should happen. It has been agreed that there are two types of values: terminal values which provide us with our goals and instrumental values which provide us with the means to achieve those goals. For example, the rule of law is a terminal value and the defense of basic liberties with rule of law is an instrumental value.

Whenever beliefs and values are discussed in the perspective of politics, they will always be referred to as political ideologies. Campbell has defined political ideology as:

“A particularly elaborate, close-woven and far-ranging structure of attitudes and beliefs. " (Cottam, 2007)

Political ideologies are closely interlinked political attitudes. These can be described as affective feelings and emotions both positive and/or negative and resulting action tendencies towards the entity under evaluation (O'Sears, 2003). The issue of political attitude is same as that of political opinions.

Public opinion can be defined as the public opinion maintained by the public at large or large sections of the populations. Public opinions are instrumental in determining the inclinations of masses, of what they want and which issues they resolved first. However, the 'public' in public opinion may not be homogenous at all, resulting in a 'heterogeneous' public opinion. The different public opinions may represent different sections of population; ethnic and racial groups and minorities. There is another problem concerning public opinion: the perception of public opinion by the government. Which public opinion seems legitimate to the regime is a matter of political attitudes deemed legitimate by the ruling regime. 
This is not to suggest that public opinion is not important. Public opinion is instrumental in determining public policy which is the primary function of elected political executives. Public opinion can be reflected in foreign policy and dealings with international community. Attitudes of politicians should be representative of public opinion otherwise; they will quickly lose their standing with the masses.

Public opinion however is given importance in democratic countries where the ruling regime is accountable to the masses. In authoritarian countries, there is a great chasm in the opinions of the regime and that of the public opinion. Nonetheless, public opinions can often become the cause of great political upheavals and revolutions. The advent of 'social media' has effectively precipitated the formation of public opinion. Today, democratic or authoritarian, states are more susceptible to public opinion and therefore play an important role in shaping and manipulating it (Woshinsky, 2008).

\section{B. Propaganda}

Political campaign managers attempt to mold and sway public opinion in favor of their own candidate while elected politicians have their own 'spin doctors' who put a positive turn on the events reported. When a country goes to war, the government attempts to infuse a spirit of patriotism in the populace to give the required sacrifices and combat the enemy. Corporate leaders promote the products fashioned by their companies to convince the customers that their products are better than the ones made by their competitors.

The common element in all of these activities is persuasion and the objective seems to be the reinforcement or modification of beliefs, attitudes and behavior of a particular audience. This is a tricky business which necessitates careful management of information. This process in its entirety is called as propaganda. The term propaganda is much more than promoting a political ideology, and in essence includes a host of activity including lobbying and commercial advertising.

Propaganda has a negative connotation because of the purposes for which it is used and the methods through which it are used. Propagandists rely on selective use of information and usually present one-sided messages which are neither true nor false, but lie somewhere between. Propaganda appeals more to emotions and prejudice than intellect, in this sense propaganda is closer to indoctrination than education. Propaganda has existed throughout history. Commanders have used propaganda to boost the morale of their soldiers and demoralize their enemies while rulers have used it to convince the people that their rule is legitimate. It can be said if politics is the art of persuasion then propaganda is its constant currency. Architectural hallmarks were built and technological strides taken by the few to inspire respect and awe in the many. The word propaganda has its root in the missionary organization built by Pope Gregory XV in 1622 named as Congregatio de Propaganda Fide (Roy, 2010). The negative connotation usually attached with the word propaganda has to do with the great wars of the twentieth century.

Due to rapid advancements in mass-communication technologies, propaganda became a major weapon during the First World War. Governments engaged in denigrating their enemies through inflammatory rhetoric, prejudice, xenophobia, half-truths and lies were exposed to discredit opposing nations. Atrocities committed by the enemies were despicably pictured in the newspapers to arouse public sympathy for the government and the war effort. The techniques of propaganda were refined to their finest level by totalitarian and fascist governments so that people's opinion can be made coherent with ruling party's policies and ideology. Joseph Goebbels, Hitler's information minister claimed that he had made the Third Reich and the claim was almost true. He broadcasted messages of hate through every conceivable medium from newspapers to Olympic Games to project images of Aryan power accompanied with bogus racial theories. Many elements of this type of propaganda were picked up by less authoritarian regimes. Every US president has tried to project the right kind of image to the public especially in the age of television and internet. The image of George W. Bush as he was flown onto the USS Abraham Lincoln by a fixed wing aircraft projected the image of a warrior among warriors to the world (Oberst M., 2013).

\section{Revolution}

Revolution is the idea of transforming the world and curing its evils once and for all. The idea of revolution has long exercised a powerful influence on public psyche. The prospect of a radical break with the past crystallized by the French Revolution which caused William Wordsworth to say the following words 'Bliss was it in that dawn to alive, but to be young was very heaven'.

Karl Marx defined revolution as the forcible overthrow of all existing social conditions. This means that such an upheaval would bring a radical transformation from one state to another. For a revolution to precipitate there must be 
some old regime which proves to be sufficiently dysfunctional and hence render itself vulnerable to revolutionary activity. The old regime must have a host of social and political institutions which have some legitimacy so that it can command motivation from the revolutionaries.

However, a revolution must encompass into two steps: destructive and constructive. The destructive phase must sweep away the old structures and put in place new structures and system- 'Novus ordo seclorum'. Revolutions are mostly constructive in the way that they are both ideological i.e. they have a specific framework of ideas and they hold out a promise for a better tomorrow.

\section{Political Violence}

Politics foresees violence. The existence of violence or its very threat motivates people to form societies in which government is entrusted to the state. It is for this particular reason that the state claims 'monopoly on the legitimate use of violence.' It means that the state reserves an exclusive right to exercise physical force against external enemies and its own citizens, when they break the rules. Such was the contention of political theorists of $17^{\text {th }}$ century like Thomas Hobbes who said, without the restraining effect of state, man would continually live in a state of nature which is characterized by continual fear and danger of violent death.

The major difference between violence and political violence is that the perpetrator of political violence will always have legitimacy. Therefore it can be said that one man's terrorist is another man's freedom fighter. Every state, by default, calls violence against itself illegal no matter what the conditions are (Chahbra, 2002). Dissent however does not always have a violent consequence; some justly constituted societies have legal channels through which differences of opinion can be channeled. When such channels fail to exist, individuals such as Martin Luther King may rise and question the legitimacy of the state.

\section{E. Political Alienation}

Political alienation has been defined as states of apathy towards major political activities garnered to bolster public participation in politics (Cottam, 2007). Political alienation has been a recent phenomenon in the realm of political science. Statistics around the world have concluded that political participation has been on the decline since 1990s even in the developed liberal democracies in the West. This goes on to show that the process of political decision making has alienated the public, who is apathetic towards politics which is shown by poor voter turnout ratios.

Political alienation is also constituted along various social hierarchies including: class, race, sex, educational background, profession and religious background. Political alienation may more of an issue in a certain class of the society than the society as a whole. Marginalized political groups are said to be politically alienated. This takes place when the marginalized political groups confer a negative value on their self-identity and justify their position in the social hierarchy. However, when the marginalized political group confers a positive value on their self-identity and seeks to change the status quo, then it changes political alienation and involves itself in political participation whether conventional or unconventional (Jost, 2004).

\section{Conclusion}

In sum, all actors combine with the processes outlined in the paper to give a range of consequences, some of which are too general and well-known to have been documented in the paper. Such consequences may include formation of a new political government, constitution of a new political regime and political coup d'état.

\section{References}

Boix, Carles \$ Stokes, C. Susan.(Ed.) (2007). The Oxford Handbook of Comparative Politics. New York, USA: Oxford University Press. P-220.

Chahbra, H.S. (2002), "Islamic World and Terrorism”, World Focus, Volume 23, Focus World Series, P-201.

Cottam, Uhler, Masters and Preston. (2007). Introduction to Political Psychology. London, UK: Lawrence Bribaum, Associates Publishers. P-10.

Class, Locality and Ideology. Houndsmill, UK: MacMillan Press Ltd. P-69.

De Zavala, A.G., Cislak, A. \& Wesolowska, E. (2010). Political Conservatism, Need for Cognitive Closure, and Intergroup Hostility, Political Psychology, 31(4), 521-542. 
Green, D., Palmquist, B. \& Schickler, E. (2002). Partisan Hearts and Minds Political Parties and the Social Identities of Voter, New Haven, USA: Yale University Press. P-24.

Huemer, Michael. (2013). The Problem of Political Authority An Examination of the Right to Coerce and the Duty to Obey. Houndsmill, UK: Palgrave Macmillan. P-56.

Hull, S. Matthew (2012), Government of Paper: The Materiality of Bureaucracy in Urban Areas, University of California, USA, P-260.

Jost, T.J. \& Sidanius, J. (Ed.) (2003). Political Psychology Key Readings in Social Psychology. New York, USA: Psychology Press. P- 88.

O’Sears, David, Huddy \& Jervis, R.(Ed.) (2003). Oxford Handbook of Political Psychology. New York, USA: Oxford University Press. P -90.

Oberst, Malik, Kennedy and Kapoor (2013), Government and Politics in South Asia, Westview Press, India, P-244.

Rees, G., Bujra, J., Littlewood, P., Newby, H. \& Rees, Teresa L. (Ed.) (1985). Political Action and Social Identity

Roy, Olivier. (2014). Holy Ignorance: When Religion and Culture Part Ways. London, UK: Oxford University Press. P- 124.

Scwartz. H.S., Caprara, G.V. \& Vecchione, M. (2010). Basic Personal Values, Core Political Values and Voting: A Longitudinal Analysis, Political Psychology, 3(13), 421-453.

Taylor, Gary \& Spencer, Steve. (Ed.) (2004). Social Identities Multidisciplinary Approaches. New York, USA: Routledge. P-118.

Woshinsky, Oliver. H. (2008). Explaining Politics, Culture, Institutions and Political Behavior. London, UK:

Routledge. P-21. 